\title{
A massive abdominal wall desmoid tumor occurring in a laparotomy scar: A case report
}

\author{
Joseph K Wanjeri", Collins JO Opeya
}

\begin{abstract}
Introduction: Desmoid tumors are benign but locally aggressive tumors of mesenchymal origin which are poorly circumscribed, infiltrate the surrounding tissue, lack a true capsule and are composed of abundant collagen. History of trauma to the site of tumor origin is elicited in up to 1 in 4 cases and they most commonly develop in the anterior abdominal wall and shoulder girdle but they can arise in any skeletal muscle. The clinical behavior and natural history of desmoid tumors are unpredictable and management is difficult with many issues remaining controversial, mainly regarding early detection, the role, type and timing of surgery and the value of non-operative therapies.

Case presentation: We report a case of a 23 year old male referred from a district hospital to a national referral hospital in Kenya, after developing a huge abdominal wall desmoid tumor following laparotomy for a blunt abdominal injury fourteen months earlier. The tumor was successfully excised and the abdominal wall defect reconstructed using a vicryl/prolene mesh and a unilateral groin flap. The patient had a non-eventful recovery and was discharged through radiotherapy clinic.
\end{abstract}

Conclusion: Wide margin tumor excision alone is a reasonable option in the management of desmoid tumors.

\section{Introduction}

Desmoid tumors account for $0.3 \%$ of all neoplasms and less than $3 \%$ of all soft tissue tumors with the estimated incidence in the general population being 2-4 per million of population per year [1-3]. Affected patients mostly fall within the age range 10-40 years with those younger than 10 years or older than 44 being affected rarely [1].

The myofibroblast is the cell considered responsible for the development of desmoid tumors but the mechanisms of development and regulation of their growth are unknown $[1,4,5]$. Trauma may have a triggering effect in the development of the tumors and the tumors may be solitary or multiple $[1,6]$. Extra-abdominal and intra-abdominal forms of the disease have been distinguished and in abdominal wall disease, the tumor is usually confined to the musculature and the overlying aponeurosis or fascia but the neoplasm may infiltrate the surrounding tissue up to $2-3 \mathrm{~cm}$ outside the palpable tumor $[3,7,8]$.

\footnotetext{
* Correspondence: onejerry@yahoo.com

Department of Surgery, School of Medicine, University of Nairobi, Kenya
}

The clinical behaviour and natural history of desmoid tumors remain unpredictable and enigmatic: while in some patients it progresses rapidly and aggressively, in others it is more indolent and may remain stable without any subsequent problem for sometime [6]. Most desmoid tumors are slow-growing neoplasms that do not metastasize but aggressively invade surrounding tissues and organs or may compress surrounding structures [3,6]. Desmoid tumors often arise from the rectus abdominis muscle in postpartum women and in scars of previous abdominal incisions $[9,10]$. Imaging methods including ultrasonography, Computed Tomography (CT) and Magnetic Resonance Imaging (MRI) are used for diagnosis and evaluation of these tumors [9].

\section{Case presentation}

The patient was a 23 year old male who presented with an anterior abdominal wall mass in December 2007 following an emergency laparotomy for blunt abdominal trauma in June 2006. He was referred to Kenyatta National Hospital from a district hospital where an incisional biopsy had been done and reported as benign
() Biomed Central

(c) 2011 Wanjeri and Opeya; licensee BioMed Central Ltd. This is an Open Access article distributed under the terms of the Creative Commons Attribution License (http://creativecommons.org/licenses/by/2.0), which permits unrestricted use, distribution, and reproduction in any medium, provided the original work is properly cited. 
fibromatosis. There was no family history of Familial Adenomatous Polyposis (FAP), colorectal disease or similar condition in any of the close relatives.

On examination, his general condition was fair and he had a huge ulcerated anterior abdominal wall mass with everted edges measuring $16 \mathrm{~cm} \times 20 \mathrm{~cm}$ (figure 1) which was reported as desmoid tumor after incisional biopsy was done. An abdominal CT scan showed hepatomegaly and a mass measuring $16 \mathrm{~cm} \times$ $15 \mathrm{~cm} \times 4.6 \mathrm{~cm}$ confined to the anterior abdominal wall with an intra-abdominal extension but no involvement of intra abdominal organs (figure 2). Neither genetic testing for the Adenomatous Polyposis Coli (APC) gene mutation nor screening with colonoscopy for adenomatous polyposis coli or colorectal cancer was performed.

In January 2008, the tumor weighing an estimated two kilograms (figure 3) was excised with a $3 \mathrm{~cm}$ macroscopic margin and the resultant defect (figure 4) reconstructed with a vicryl/prolene mesh. A left local fasciocutaneous groin flap was rotated to cover the mesh and the secondary defect on the left groin area covered with a split thickness skin graft. The patient had a non-eventful postoperative recovery period and was discharged through radiotherapy clinic but he missed his appointment. The authors traced him thirty months later and found him without any sign of recurrence but he had an incisional hernia at the site of tumor excision and repair (figure 5).

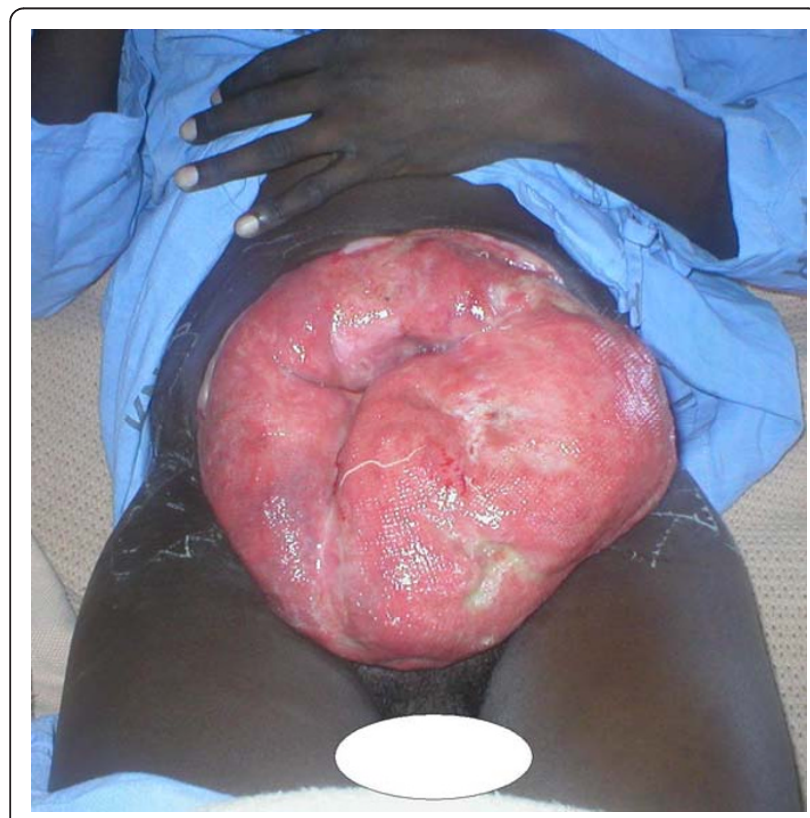

Figure 1 The ulcerated anterior abdominal wall tumor with everted edges.



Figure 2 CT scan of the abdomen showing the anterior abdominal wall tumor.

\section{Discussion}

Desmoid tumors are monoclonal fibroblastic proliferations arising in musculoaponeurotic structures. They are benign but aggressive tumors of mesenchymal origin, forming a heterogenous group of pathologic entities resulting from the proliferation of well-differentiated fibroblasts $[11,12]$. At microscopy, desmoid tumors are poorly circumscribed, infiltrate the surrounding tissue, lack a true capsule and are composed of abundant collagen surrounding poorly circumscribed bundles of elongated, slender, spindleshaped cells of uniform appearance [9].

Most desmoid tumors occur sporadically but about 2$5 \%$ commonly occur in the abdominal cavity or abdominal wall in association with FAP [6]. Inheritance (or new mutation) of one copy of APC tumor suppressor gene is the cause of FAP and the two commonest causes

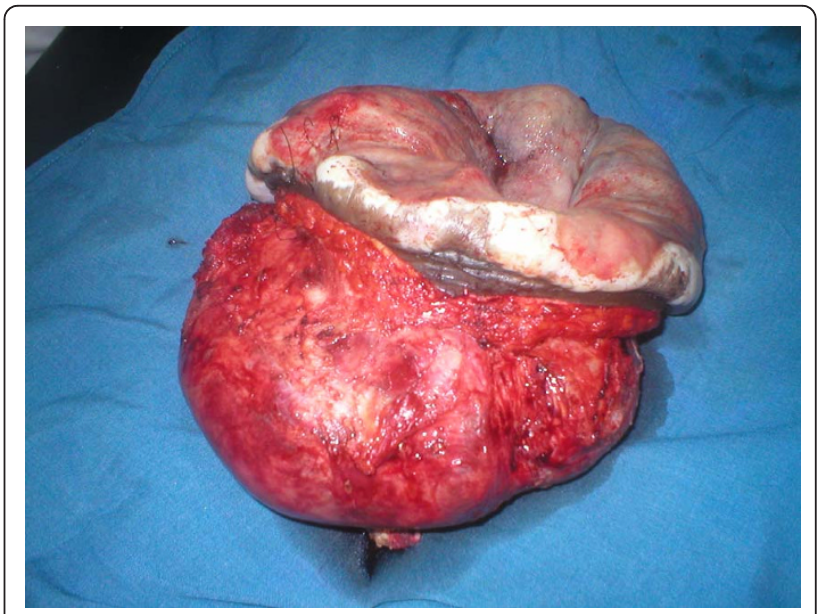

Figure 3 The excised anterior abdominal wall tumor 


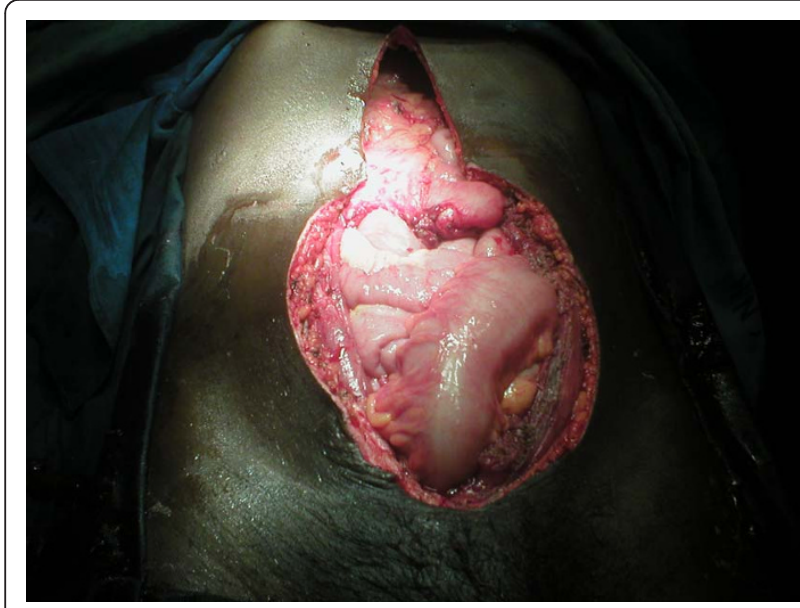

Figure 4 The resulting anterior abdominal wall defect following the excision of the tumor

of deaths in these patients are duodenal cancer and desmoid tumors [6]. In FAP associated cases, desmoid tumors represent an extra-colonic manifestation of polyposis syndrome [13]. Every patient with desmoid tumor should therefore be evaluated for the presence of associated polyposis syndrome by taking a detailed family history, performing colonoscopy and possibly upper GastroIntestinal (GI) endoscopy [1]. The patient in this report did not have a family history of polyposis and colonoscopy was not done due to financial constraints.

Management of patients with desmoid tumors is difficult and many issues remain controversial, mainly regarding early detection, the role, type and timing of surgery, and the value of non-operative therapies [1]. The main difficulty in treatment is due to the fact that these tumors are histologically benign but have a high propensity for local recurrence [3]. Women have been

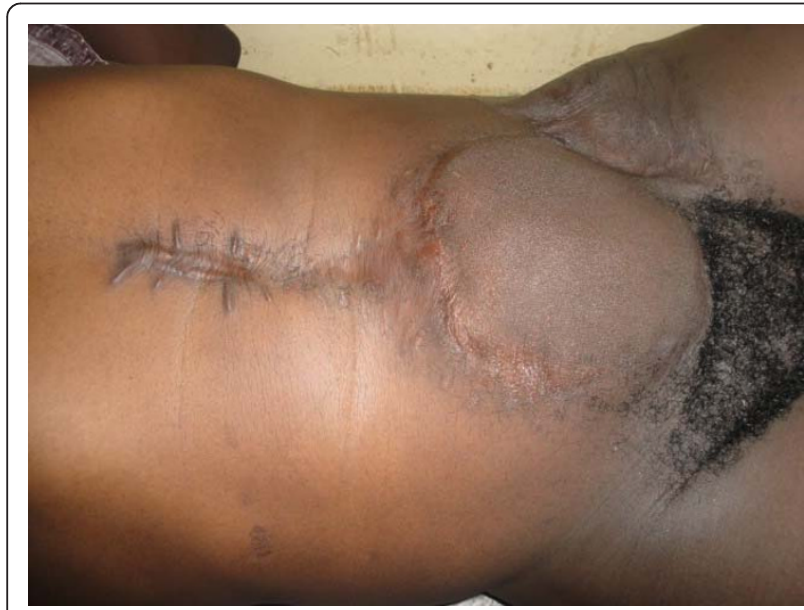

Figure 5 The anterior abdominal wall $\mathbf{3 0}$ months after excision of the tumor. Note the incisional hernia. found to be more likely to require multiple desmoid tumor resections than men, an observation which supports the hypothesis that estrogens stimulate desmoid growth [6]. Estrogen's regulatory role is supported further by the higher incidence of desmoid tumors in women during their reproductive years, the apparent tendency of tumors to develop during pregnancy or soon after, their occasional disappearance after menopause, the proliferation of similar lesions in laboratory animals by estrogen administration and the potential benefit of anti-estrogen drugs $[1,3,13,14]$.

There are no good randomized clinical trials of treatment for desmoid tumors and most studies are based on small case series. The effects of treatment are further compounded by the variable natural history of the disease with some tumors apparently regressing or remaining stable even without treatment [1].

Management of desmoid tumors involves a multidisciplinary approach with rapidly growing tumors being managed more aggressively [3]. Our patient was managed by a team of general surgeons, a plastic surgeon, a radio-oncologist, a psychological counselor, a social worker, nurses and a pathologist. Surgery is the mainstay of treatment in the management of extra-abdominal desmoid tumors and resection of abdominal wall tumors especially can be performed safely [6,9]. Radical (free margin) excision as in this case report offers the best chance for cure and of avoiding local recurrence [3]. Unfortunately, radical surgery is not always a straightforward procedure because of the tumor's extent and invasiveness. Superficial abdominal wall desmoid tumors should be resected before they become large in order to avoid having large soft tissue defects with resultant complicated and technically more demanding reconstruction [15-17]. Abdominal wall reconstruction can be achieved by direct repair (with sutures), and by using synthetic materials (meshes) or myocutaneous flaps when the defect is large as in this case report $[16,18,19]$. Surgery may also be required for the management of complications such as hemorrhage, bowel perforation, hollow visceral obstruction, peritonitis or sepsis.

Radiation therapy has been used mainly for the treatment of extra-abdominal desmoid tumors and has resulted in improvement of local control of desmoid tumors by reducing local recurrence rates [18-21]. External-beam irradiation or brachytherapy has been used alone in patients with inoperable lesions, but it has been associated with high failure rates [11,19]. Radiotherapy may also be used either before surgery or as adjuvant therapy following incomplete (non-radical) surgical resection $[2,3,6,22]$. The patient in this case report was referred to radiotherapy unit and was scheduled to receive radiotherapy following the presumed complete excision of the tumor but he defaulted treatment. $\mathrm{He}$ was traced by the authors many months post-operatively 
and clinical examination revealed an incisional hernia (figure 5) but no evidence of local tumor recurrence at the excision site indicating that wide excision alone may be adequate in the management of desmoid tumors.

The role of radiofrequency ablation in the management of these tumors is still under investigation and could be considered in selected patients and only when other treatment modalities have failed [21]. Percutaneous chemical ablation with acetic acid under radiological guidance is another therapeutic option and unproven treatments with pirfenidone, interferon alpha and glivec (imatinib, $800 \mathrm{mg} / \mathrm{d}$ ) may be effective, but only anecdotal reports or small series have been published so far [23-27]. Gene transfer therapy is also a field of intensive research currently in the management of desmoid tumors [28].

\section{Conclusion}

Desmoid tumors are rare in clinical practice and their management remains quite challenging due to their variable clinical behavior. Wide excision with tumor free margins may be adequate in the management of abdominal wall tumors as shown by the current case report.

\section{Consent}

Written informed consent was obtained from the patient for publication of this report and accompanying images. A copy of the written consent is available for review by the Editor-in-Chief of this journal.

\section{Authors' contributions}

CJOO drafted most of the initial manuscript and traced the patient in November 2010, JKW drafted parts of the manuscript and critically revised the whole manuscript before submission to the editor and publisher. Both authors read and approved the final manuscript.

\section{Competing interests}

The authors declare that they have no competing interests.

Received: 28 November 2010 Accepted: 22 March 2011

Published: 22 March 2011

\section{References}

1. Sakorafas GH, Nissotakis C, Peros G: Abdominal desmoid tumors. Surgical Oncology 2007, 16:131-142.

2. Nuyttens JJ, Rust PF, Thomas CR, Turrisi AT: Surgery versus radiation therapy for patients with aggressive fibromatosis or desmoid tumors. A comparative review of 22 articles. Cancer 2000, 88:1517-1523.

3. Papagelopoulos PJ, Mavrogenis AF, Mitsiokapa EA, Paparaskeva KT, Galanis EC, Soucacos PN: Current trends in the management of extraabdominal desmoid tumours. World Journal of Surgical Oncology 2006, 4:21-28.

4. Reitamo JJ, Scheinin TM, Hayry P: The desmoid syndrome: New aspects in the cause, pathogenesis and treatment of the desmoid tumor. American Journal of Surgery 1986, 151:230-237.

5. Lotfi AM, Dozois RR, Gordon H, Hruska LS, Weiland LH, Carryer PW, Hurt RD: Mesenteric fibromatosis complicating familial adenomatous polyposis: Predisposing factors and results of treatment. International Journal of Colorectal Disease 1989, 4:30-36.
6. Latchford AR, Sturt NJH, Neale K, Rogers PA, Phillips RKS: A 10-year review of surgery for desmoid disease associated with familial adenomatous polyposis. British Journal of Surgery 2006, 93:1258-1264.

7. Overhaus M, Decker P, Fischer HP, Textor JH, Hirner A: Desmoid tumor of the abdominal wall. World Journal of Surgical Oncology 2003, 1:11-15.

8. Antal I, Szendroi M, Kovacs Gy, Nagykalnai T, Entz L: Multicentric extraabdominal desmoid tumour: A case report. Journal of Cancer Research and Clinical Oncology 1994, 120:490-493.

9. Hartley JE, Church JM, Gupta S, McGannon E, Fazio WW: Significance of incidental desmoids identified during surgery for familial adenomatous polyposis. Diseases of the Colon and Rectum 2004, 47:334-340.

10. Casillas J, Sais GJ, Greve JL, Iparraguirre MC, Morillo G: Imaging of intraand extraabdominal desmoid tumors. Radiographics 1991, 11:959-968.

11. Moslein G, Dozois RR: Desmoid tumors associated with familial adenomatous polyposis. Perspectives in Colon and Rectal Surgery 1998, 10:109-126.

12. Sagar PM, Moslein G, Dozois RR: Management of desmoid tumors in patients after ileal-pouch-anal anastomosis for familial adenomatous polyposis. Diseases of the colon and rectum 1998, 41:1350-1355.

13. Julian N, Sturt H, Clark SK: Current ideas in desmoid tumours. Familial Cancer 2006, 5:275-285

14. Wilcken N, Tattersall MH: Endocrine therapy for desmoid tumors. Cancer 1991, 68:1384-1388.

15. Rohrich RJ, Lowe JB, Hackney FL, Bowman JL, Hobar PC: An algorithm for abdominal wall reconstruction. Plastic and Reconstructive Surgery 2000, 105:202-216

16. Bauer JJ, Salky BA, Gelernt IM, Kreel I: Repair of large abdominal wall defects with expanded polytetrafluoroethylene (PTFE). Annals of Surgery 1987, 206:765-769.

17. Lewis JJ, Boland PJ, Leung DHY, Woodruff JM, Brennan MF: The enigma of desmoid tumors. Annals of Surgery 1999, 229:866-873.

18. Sherman NE, Romsdahl M, Evans H, Zagars G, Oswald MJ: Desmoid tumors: A 20-year radiotherapy experience. International Journal of Radiation Oncology Biology Physics 1990, 19:37-40.

19. O'Dea FJ, Wunder J, Bell RS, Griffin AM, Catton C, O'Sullivan B: Preoperative radiotherapy is effective in the treatment of fibromatosis. Clinical Orthopaedics and Related Research 2003, 415:19-24.

20. Duggal A, Dickinson IC, Sommerville S, Gallie P: The management of extraabdominal desmoid tumors. International Orthopaedics 2004, 28:252-256.

21. Micke O, Seegenschmiedt MH: Radiation therapy for aggressive fibromatosis (desmoid tumors): Results of a national patterns of care study. International Journal of Radiation Oncology Biology Physics 2005, 61:882-91.

22. Sutton RJ, Thomas JM: Desmoid tumours of the anterior abdominal wall. European Journal of Surgical Oncology 1999, 25:398-400.

23. Clark TW: Percutaneous chemical ablation of desmoid tumors. Journal of Vascular and Interventional Radiology 2003, 14:629-634.

24. Hardell L, Breivald M, Hennerdal S: Shrinkage of desmoid tumor with interferon alfa treatment: A case report. Cytokines Cellular \& Molecular Therapy 2000, 6:155-156

25. Lindor NM, Dozois R, Nelson H, Wolff B, Kina J, Boardman L, Wilson M, Greene MH, Karnes W, Mesa R, Welch T, Edmonson J, Limburg P: Desmoid tumors in familial adenomatous polyposis: A pilot project evaluating the efficacy of treatment with pirfenidone. American Journal of Gastroenterology 2003, 98:1868-1874.

26. Mace J, Biermann JS, Sondak V, McGinn C, Hayes C, Thomas D, Baker L: Response of extraabdominal desmoid tumors to therapy with imatinib mesylate. Cancer 2002, 95:2373-2379.

27. Heinrich MC, McArthur GA, Demetri GD, Joensuu H, Bono P, Herrmann R, Hirte H, Cresta S, Koslin DB, Corless CL, Dirnhofer S, Oosterom AT, Nikolova Z, Dimitrijevic S, Fletcher JA: Clinical and molecular studies of the effect of imatinib on advanced aggressive fibromatosis (desmoid tumor). Journal of Clinical Oncology 2006, 24:1195-1203.

28. Bright-Thomas RM, Agrawal A, Hargest R: Preclinical studies of gene transfer for the treatment of desmoid disease in familial adenomatous polyposis. British Journal of Surgery 2002, 89:1563-1569.

doi:10.1186/1477-7819-9-35

Cite this article as: Wanjeri and Opeya: A massive abdominal wall desmoid tumor occurring in a laparotomy scar: A case report. World Journal of Surgical Oncology 2011 9:35. 